\title{
Clinical Significance of Tyrosine Hydroxylase mRNA Transcripts in Peripheral Blood at Diagnosis in Patients with Neuroblastoma
}

\author{
Na Hee Lee, MD ${ }^{1}$ \\ Meong Hi Son, $\mathrm{MD}^{2}$ \\ Young Bae Choi, $\mathrm{MD}^{3}$ \\ Eunsang Yi, MD ${ }^{3}$ \\ Ji Won Lee, MD, $P h D^{3}$ \\ Keon Hee Yoo, MD, PhD ${ }^{3}$ \\ Ki Woong Sung, MD, $\mathrm{PhD}^{3}$ \\ Hong Hoe Koo, MD, PhD
}

${ }^{1}$ Department of Pediatrics, CHA Bundang

Medical Center, CHA University,

Seongnam, Korea, ${ }^{2}$ Princess Margaret

Cancer Centre, University Health Network,

Toronto, ON, Canada, ${ }^{3}$ Department of

Pediatrics, Samsung Medical Center,

Sungkyunkwan University School of

Medicine, Seoul, Korea

Correspondence: Ki Woong Sung, MD, PhD

Department of Pediatrics,

Samsung Medical Center, Sungkyunkwan

University School of Medicine, 81 Irwon-ro,

Gangnam-gu, Seoul 06351, Korea

Tel: 82-2-3410-3529

Fax: 82-2-3410-0049

E-mail:kwsped@skku.edu

Received December 10, 2015

Accepted March 14, 2016

Published Online March 24, 2016

${ }^{*}$ Na Hee Lee and Meong Hi Son contributed equally to this work.

\begin{abstract}
Purpose
The purpose of this study is to investigate the clinical significance of tyrosine hydroxylase $(T H)$ expression in peripheral blood (PB) at diagnosis in patients with neuroblastoma.

\section{Materials and Methods}

TH mRNA expression in PB was measured by reverse transcription quantitative real-time polymerase chain reaction in 210 patients who were newly diagnosed with neuroblastoma from July 2005 to June 2015 and the clinical significance of TH expression in PB at diagnosis was evaluated.
\end{abstract}

\section{Results}

$\mathrm{TH}$ expression was positive in 60 patients (28.6\%). Fifty of $60 \mathrm{TH}$-positive patients had metastatic tumors and the remaining 10 had localized tumors. TH expression was associated with high-risk features (i.e., advanced stage, older age, unfavorable pathology, and MYCN amplification) at diagnosis. Among TH-positive patients, higher TH expression level was observed in high-risk patients than in low- or intermediate-risk patients $(p=0.035)$. The probability of 5-year progression-free survival (PFS) was lower in $T H$-positive patients than in $T H$-negative patients $(63.8 \pm 6.9 \%$ vs. $94.7 \pm 2.1 \%, p<0.001)$. In analysis confined to high-risk patients, the 5-year probability of PFS remained lower in TH-positive patients (55.7 $\pm 8.2 \%$ vs. $89.6 \pm 5.8 \%, p<0.001)$. Among $T H$-positive patients, a higher expression level of $T H$ was associated with a worse outcome. In multivariate analyses, positive $\mathrm{TH}$ expression in PB at diagnosis was an independent poor prognostic factor for PFS.

\section{Conclusion}

The treatment intensity should be tailored according to TH expression in PB at diagnosis.

\section{Introduction}

Neuroblastoma (NB) is a common childhood solid tumor that presents with clinical heterogeneity. The presentation of NB can range from localized tumors to disseminated forms, which have different prognoses and require different treatment $[1,2]$. Therefore, determining the disease extent and stage at the time of diagnosis is important. A number of

\section{Key words}

Neuroblastoma, Tyrosine 3-monooxygenase,

Polymerase chain reaction 
minimal disease in NB [5-8].

According to our preliminary reports, positive $\mathrm{TH}$ expression in $\mathrm{PB}$ at diagnosis is a poor prognostic factor [9]. However, the number of patients was small and the followup duration was short. In the current study, we evaluated the significance of $\mathrm{TH}$ expression in a larger cohort of patients with a longer follow-up period as well as the clinical implications of the level of $\mathrm{TH}$ expression among $\mathrm{TH}$-positive patients.

\section{Materials and Methods}

Written informed consent for $\mathrm{TH}$ analysis was obtained at diagnosis from all patients or guardians. This retrospective study was approved by the Institutional Review Board (IRB) of Samsung Medical Center and the requirement for informed consent was waived (IRB 2014-12-090).

\section{Patients}

Medical records of all patients who were newly diagnosed with NB over a 10-year period from July 2005 to June 2015 were reviewed retrospectively. Patients were staged according to the International Neuroblastoma Staging System [10] and disease extent was evaluated using computerized tomography (CT), magnetic resonance imaging (MRI), technetium-99 bone scans, bilateral BM aspirates and biopsy specimens, and ${ }^{131} \mathrm{I}$ - or ${ }^{123}$ I-metaiodobenzylguanidine (MIBG) scanning. Measurement of TH expression in PB was included in routine evaluation at diagnosis. MYCN amplification was determined using competitive polymerase chain reaction (PCR), RT-qPCR, or fluorescence in situ hybridization. Tumors were classified as histologically favorable or unfavorable according to the International Neuroblastoma Pathology Classification [11]. Measurement of serum lactic dehydrogenase (LDH), ferritin, neuron-specific enolase (NSE), and urine vanillylmandelic acid (VMA) was also included in routine evaluation at diagnosis. Patients were stratified into low-risk, intermediate-risk, and high-risk groups based on age, stage, and MYCN status. Stage 1, 2, and $4 \mathrm{~S}$ tumors without MYCN amplification were stratified as

Table 1. Conventional and HDCT regimens

\begin{tabular}{|c|c|c|}
\hline Regimen/Drug & Dose & Treatment days \\
\hline \multicolumn{3}{|l|}{ Conventional chemotherapy regimen } \\
\hline \multicolumn{3}{|l|}{ CEDC } \\
\hline Cisplatin (mg/m²/ dose) & 60 & 0 \\
\hline Etoposide $\left(\mathrm{mg} / \mathrm{m}^{2} /\right.$ dose $)$ & 100 & 2,5 \\
\hline Doxorubicin (mg/m²/ dose) & 30 & 2 \\
\hline Cyclophosphamide (mg/kg/dose) & 30 & 3,4 \\
\hline \multicolumn{3}{|l|}{ ICE $\left(\mathrm{mg} / \mathrm{m}^{2} /\right.$ dose $)$} \\
\hline Ifosfamide & 1,200 & $0-4$ \\
\hline Carboplatin & 400 & $0-1$ \\
\hline Etoposide & 100 & $0-4$ \\
\hline \multicolumn{3}{|l|}{ First HDCT regimen $\left(\mathrm{mg} / \mathrm{m}^{2} / \mathrm{dose}\right)$} \\
\hline Carboplatin & 650 & $-7,-6,-5$ \\
\hline Etoposide & 650 & $-7,-6,-5$ \\
\hline Cyclophosphamide & 1,800 & $-4,-3,-2$ \\
\hline \multicolumn{3}{|l|}{ Second HDCT regimen } \\
\hline \multicolumn{3}{|l|}{ 2004-2008 } \\
\hline Thiotepa (mg/m²/ dose) & 200 & $-8,-7,-6$ \\
\hline Melphalan (mg/m²/ dose) & 60 & $-5,-4$ \\
\hline TBI (Gy / dose) & 3.33 & $-3,-2,-1$ \\
\hline \multicolumn{3}{|l|}{ 2009-2015 } \\
\hline Thiotepa (mg/m²/ dose) & 200 & $-6,-5,-4$ \\
\hline Melphalan (mg/m²/ dose) & 60 & $-3,-2$ \\
\hline${ }^{131} \mathrm{I}-\mathrm{MIBG}(\mathrm{mCi} / \mathrm{kg})$ & 12 or 18 & -21 \\
\hline
\end{tabular}

HDCT, high-dose chemotherapy; TBI, total body irradiation; ${ }^{131} \mathrm{I}-\mathrm{MIBG},{ }^{131}$ I-metaiodobenzylguanidine. 
low-risk tumors whereas stage 4 tumors in patients older than 12 months or any tumors with amplified MYCN were stratified as high-risk tumors. All other tumors were stratified as intermediate-risk.

\section{Treatment}

Excisional biopsy of the primary tumor was performed at diagnosis for resectable tumors. Otherwise, incisional or percutaneous needle biopsy was performed with definitive surgery after six chemotherapy cycles. Alternating CEDC (cisplatin+etoposide+doxorubicin+cyclophosphamide) and ICE (ifosfamide+carboplatin+etoposide) regimens were used for chemotherapy (Table 1). Patients with low-risk localized tumors underwent surgery with (stage 2) or without (stage 1) six cycles of preoperative or postoperative chemotherapy. Patients with low-risk stage $4 S$ tumors were treated only when there were life-threatening symptoms or the tumor progressed during observation. Patients with intermediaterisk tumors received six cycles of preoperative chemotherapy, surgery, three cycles of postoperative chemotherapy, and 12 cycles of 13 -cis-retinoic acid $\left(125 \mathrm{mg} / \mathrm{m}^{2} /\right.$ day for 14 days every 4 weeks). Local radiotherapy to the primary site was administered if gross residual tumor remained after surgery. Patients with high-risk tumors received tandem high-dose chemotherapy and autologous stem cell transplantation (HDCT/auto-SCT) after induction treatment (six cycles of preoperative chemotherapy, surgery, and three cycles of postoperative chemotherapy). The CEC (carboplatin+etoposide+cyclophosphamide) regimen was used for the first HDCT. The second HDCT regimen was TM-TBI (thiotepa+melphalan+total body irradiation) for patients diagnosed up to December 2008. For patients diagnosed from January 2009 onwards, TBI was replaced with highdose ${ }^{131} \mathrm{I}$-MIBG (12 or $18 \mathrm{mCi} / \mathrm{kg}$ ) to reduce late adverse effects. Local radiotherapy was applied to the primary site in all high-risk patients approximately 6 weeks after the second HDCT/auto-SCT. Differentiation therapy involving 13-cis-retinoic acid with immunotherapy using interleukin 2 $\left(2 \times 10^{6} \mathrm{U} / \mathrm{m}^{2} /\right.$ day for 5 days every 4 weeks) was administered until 1 year after HDCT / auto-SCT to reduce relapse from minimal residual tumor cells [12].

\section{RT-qPCR for TH expression analysis}

PB samples were collected at diagnosis in ethylenediaminetetraacetic acid tubes and mononuclear cells were separated and lysed in TRIzol reagent (Invitrogen Corporation, Carlsbad, CA). RNA was extracted according to the manufacturer's instructions and $1 \mu \mathrm{g}$ of RNA was used to generate $20 \mu \mathrm{L}$ of complementary DNA using an RNA PCR kit (Applied Biosystems, Foster City, CA). RT-qPCR was performed using Real-Q TH Quantification Kits (BioSewoom, Seoul, Korea) on a LightCycler (Roche Diagnostics, Mannheim, Germany). RT-qPCR was performed under the following cycling conditions: denaturation at $95^{\circ} \mathrm{C}$ for 10 minutes, 45 cycles at $95^{\circ} \mathrm{C}$ for 10 seconds, $60^{\circ} \mathrm{C}$ for 10 seconds, and $72^{\circ} \mathrm{C}$ for 30 seconds, followed by a cooling step at $40^{\circ} \mathrm{C}$ for 30 seconds. Reactions were performed in a $20-\mu \mathrm{L}$ volume containing PCR reaction mixture, TaqMan probe (5'FAM AGCGCAGGAAGCTGATTGCTGAGTAMRA-3'), primer mixture (forward, 5'-TCATCACCTGGTCACCAAGTT -3'; reverse, 5'-GGTCGCCGTGCCTGTACT-3'), $2 \mu \mathrm{L}$ cDNA, and sterile water. The $A B L$ gene was used as a control gene in RT-qPCR. If the expression value of $A B L$ in the RT-qPCR amplification was less than a copy number of 104, the sample was considered inadequate for RT-qPCR analysis and the RNA extraction was repeated. The quantity of $T H$ transcripts was normalized to the $A B L$ transcript level, and the result was expressed as the ratio of the $T H$ to $A B L$ transcript copy number.

\section{Statistics}

Pearson's chi-squared test was used for comparison of frequencies between groups. The Mann-Whitney U test was used for comparison of continuous variables between groups. Progression-free survival (PFS) and overall survival (OS) rates with standard errors were estimated using the Kaplan-Meier method. Relapse was regarded as progression in the statistical analysis. Differences in PFS rates between groups were compared using the log-rank test. Multivariate analyses of prognostic factors for PFS and OS were performed using Cox regression analysis. p-values less than 0.05 were considered significant.

\section{Results}

\section{Patient characteristics}

A total of 210 patients (118 boys and 92 girls) were evaluated for the presence of TH mRNA in PB at diagnosis. The clinical and biological characteristics of patients are shown in Table 2. The median age at diagnosis was 22 months (range, 0 to 232 months) and median follow-up duration was 51 months (range, 1 to 122 months). At diagnosis, 134 patients were older than 12 months, 103 patients had metastatic tumors including four stage $4 S$ tumors, 90 had histologically unfavorable tumors, and 34 had MYCN amplified tumors. Among 89 patients with high-risk tumors, 30 patients used TM-TBI regimen in the second HDCT/ 
Table 2. Clinical and biological characteristics with respect to $T H$ expression

\begin{tabular}{|c|c|c|c|}
\hline Variable & TH-negative (n=150) & TH-positive $(\mathrm{n}=60)$ & p-value \\
\hline \multicolumn{4}{|l|}{ Sex } \\
\hline Female $(\mathrm{n}=92)$ & $66(71.7)$ & $26(28.3)$ & 0.930 \\
\hline Male (n=118) & $84(71.2)$ & $34(28.8)$ & \\
\hline \multicolumn{4}{|l|}{ Age } \\
\hline$<12$ mo $(\mathrm{n}=76)$ & $65(85.5)$ & $11(14.5)$ & 0.001 \\
\hline$\geq 12 \mathrm{mo}(\mathrm{n}=134)$ & $85(63.4)$ & $49(36.6)$ & \\
\hline \multicolumn{4}{|l|}{ INSS stage } \\
\hline Stage $1(\mathrm{n}=35)$ & $32(91.4)$ & $3(8.6)$ & $<0.001$ \\
\hline Stage $2(n=29)$ & $27(93.1)$ & $2(6.9)$ & \\
\hline Stage $3(n=43)$ & $38(88.4)$ & $5(11.6)$ & \\
\hline Stage $4(n=99)$ & 49 (49.5) & $50(50.5)$ & \\
\hline Stage $4 S(n=4)$ & $4(100)$ & 0 & \\
\hline \multicolumn{4}{|l|}{ Pathology } \\
\hline Favorable (n=115) & $91(79.1)$ & $24(20.9)$ & 0.008 \\
\hline Unfavorable $(\mathrm{n}=90)$ & $56(62.2)$ & $34(37.8)$ & \\
\hline Unknown $(\mathrm{n}=5)$ & $3(60.0)$ & $2(40.0)$ & \\
\hline \multicolumn{4}{|l|}{ MYCN } \\
\hline Non-amplified ( $\mathrm{n}=172)$ & $128(74.4)$ & $44(25.6)$ & 0.012 \\
\hline Amplified (n=34) & $18(52.9)$ & $16(47.1)$ & \\
\hline Unknown (n=4) & $4(100)$ & 0 & \\
\hline \multicolumn{4}{|l|}{ Risk group } \\
\hline Low $(\mathrm{n}=65)$ & $59(90.8)$ & $6(9.2)$ & $<0.001$ \\
\hline Intermediate $(\mathrm{n}=57)$ & $50(87.7)$ & $7(12.3)$ & \\
\hline High $(\mathrm{n}=88)$ & $41(46.6)$ & 47 (53.4) & \\
\hline LDH (IU/L) & $702(273-10,000)$ & $1,480(305-15,720)$ & $<0.001$ \\
\hline Ferritin (ng/mL) & $80(8-893)$ & $267(3-1,639)$ & $<0.001$ \\
\hline NSE (ng/mL) & $23(3-1,443)$ & $99(7-1,815)$ & $<0.001$ \\
\hline Urine VMA (mg/day) & $4.0(0.2-205.0)$ & $14.7(0.1-100.0)$ & $<0.001$ \\
\hline
\end{tabular}

Values are presented as number (\%) or median (range). TH, tyrosine hydroxylase; INSS, International Neuroblastoma Staging System; LDH, lactate dehydrogenase; NSE, neuron-specific enolase; VMA, vanillylmandelic acid.

auto-SCT and the remaining 59 patients used ${ }^{131}$ I-MIBG-TM regimen.

\section{RT-qPCR analysis of $T H$ expression in PB}

TH expression was positive in $\mathrm{PB}$ at diagnosis in 60 of 210 patients $(28.6 \%)$. The median expression level $(\mathrm{TH} / \mathrm{ABL}$ ratio) of TH mRNA transcript detected in PB was $1,580 \times 10^{-6}$ (range, $2 \times 10^{-6}$ to $3,711,864 \times 10^{-6}$ ). Positive TH expression was associated with high-risk features (i.e., advanced stage, older age, unfavorable pathology, and MYCN amplification). The levels of serum LDH, ferritin, NSE, and urine VMA were also higher in TH-positive patients (Table 2). Among $60 \mathrm{TH}$-positive patients, 50 had metastatic tumors and the remaining 10 had localized tumors (stage 1 in three, stage 2 in two, and stage 3 in five patients). Among the TH-positive patients, a higher $\mathrm{TH}$ expression level was associated with advanced stage and high-risk tumor, but not with older age ( $\geq 12$ months) or MYCN amplification (Fig. 1A-D).

\section{Survival according to $T H$ expression at diagnosis}

Relapse or progression occurred in 19 of $60 \mathrm{TH}$-positive patients (31.7\%), compared with only six of $150 \mathrm{TH}$-negative patients $(4.0 \%)$. Lower 5-year probabilities of PFS and OS were observed in $\mathrm{TH}$-positive patients than in $\mathrm{TH}$-negative patients (PFS: $63.8 \pm 6.9 \%$ vs. $94.7 \pm 2.1 \%, \mathrm{p}<0.001$; OS: $70.2 \pm$ $6.7 \%$ vs. $92.4 \pm 2.5 \%, \mathrm{p}<0.001$ ) (Fig. $2 \mathrm{~A}$ ). In analysis confined to only high-risk patients, the 5-year probabilities of PFS and OS remained lower in TH-positive patients (PFS: $55.7 \pm 8.2 \%$ vs. $89.6 \pm 5.8 \%, p=0.001$; OS: $61.4 \pm 8.1 \%$ vs. $87.2 \pm 6.1 \%, p=0.064$ ) (Fig. 2B). However, in low- and intermediate-risk patients, no difference in the 5-year probabilities of PFS and OS was observed between $\mathrm{TH}$-positive patients and $\mathrm{TH}$-negative 


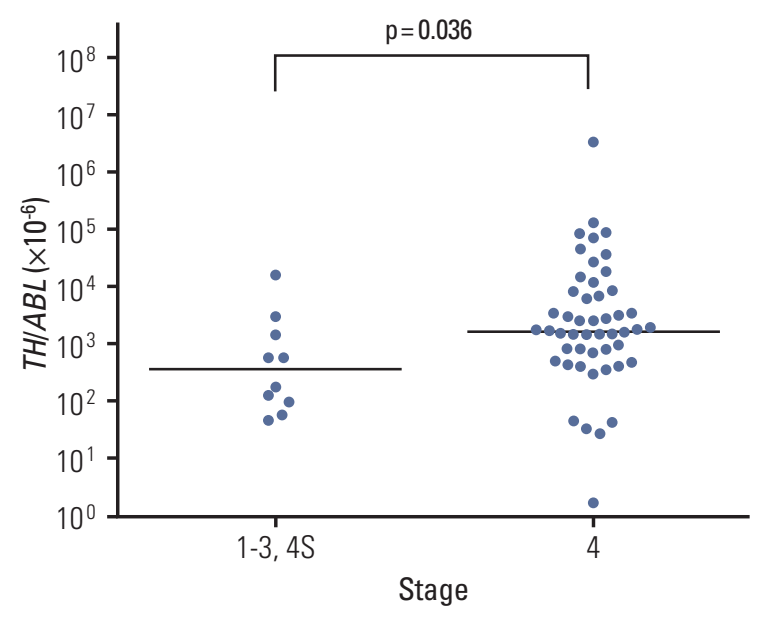

A
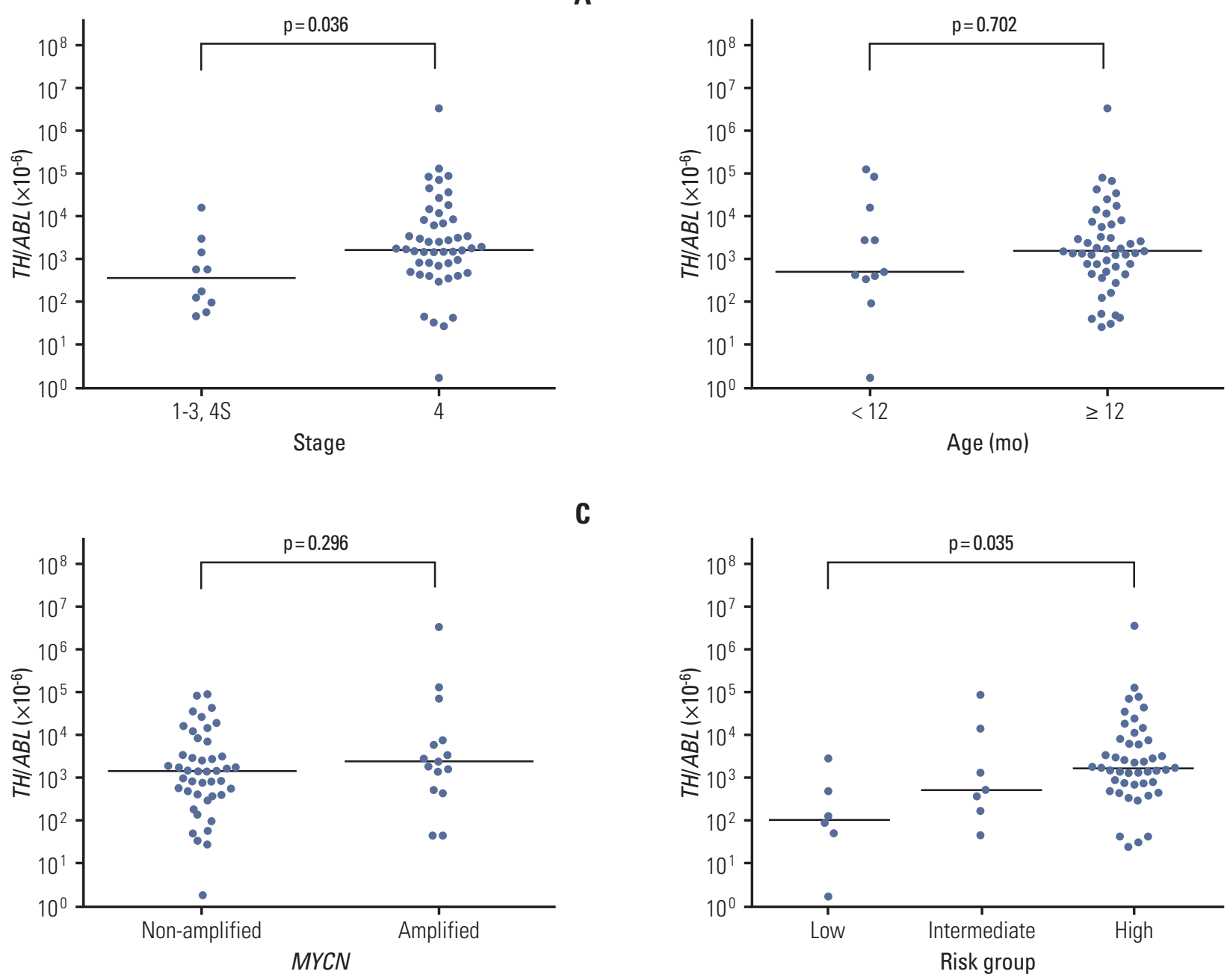

C

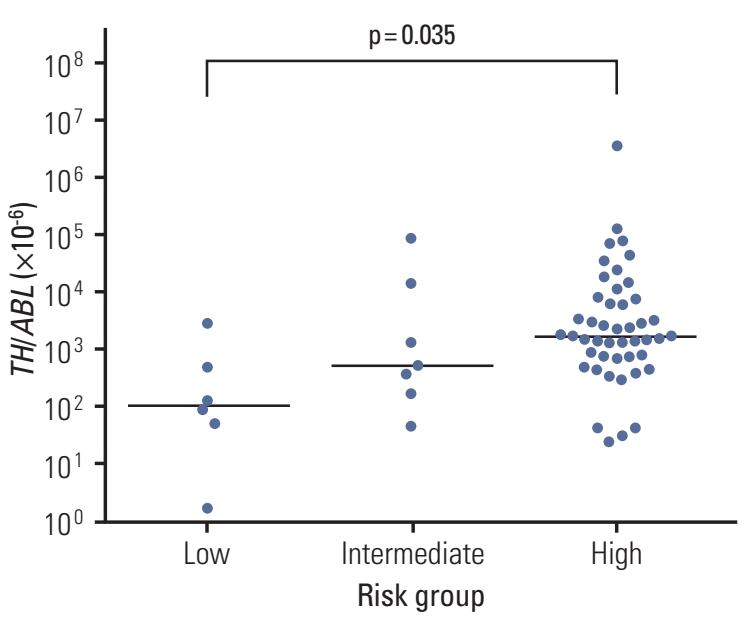

Fig. 1. Association between tyrosine hydroxylase (TH) expression level and clinicopathologic features. (A-C) Among 60 TH-positive patients, a higher level (TH/ ABL ratio) of TH mRNA transcript was associated with advanced stage (A), but not older age ( $\geq 12$ months) (B) or MYCN amplification (C). (D) TH expression level was higher in high-risk patients than in low- or intermediate-risk patients $(\mathrm{p}=0.035)$.

patients (PFS: $96.8 \pm 1.9 \%$ vs. $90.0 \pm 8.7 \%$, $\mathrm{p}=0.447$; OS: $100 \%$ vs. $94.5 \pm 2.5 \%, \mathrm{p}=0.725)$. Among high-risk patients, there was no difference in the 5-year probabilities of PFS and OS according to the HDCT regimen (TM-TBI vs. ${ }^{131} \mathrm{I}-\mathrm{MIBG}-\mathrm{TM}$ ) (PFS: $63.3 \pm 8.8 \%$ vs. $78.7 \pm 6.6 \%, \mathrm{p}=0.184$; OS: $70.0 \pm 8.4 \%$ vs. $76.7 \pm$ $6.4 \%, \mathrm{p}=0.745)$. In analysis confined to only $\mathrm{TH}$-positive highrisk patients, there was also no difference in survival rates according to the HDCT regimen (PFS: $50.0 \pm 12.5 \%$ vs. $61.2 \pm$ $10.5 \%$, $\mathrm{p}=0.523$; OS: $56.3 \pm 12.4 \%$ vs. $67.0 \pm 9.3 \%, \mathrm{p}=0.923)$. One of $10 \mathrm{TH}$-positive patients with localized tumors experienced relapse. The results of multivariate analysis for PFS and OS are shown in Table 3. Positive TH expression in PB at diagnosis was an independent factor for PFS (hazard ratio, 6.35;
95\% confidence interval, 2.10 to $19.25 ; \mathrm{p}=0.001)$. The results were similar when the analysis was confined to high-risk patients (hazard ratio, 9.02; 95\% confidence interval, 2.06 to 39.50; $p=0.004$ ) (Table 4). Among TH-positive patients, a higher expression level of $\mathrm{TH}$ was associated with a worse outcome (above median level vs. below median level: $52.9 \pm$ $10.0 \%$ vs. $75.7 \pm 8.8 \%, \mathrm{p}=0.075$ for 5 -year PFS; $55.9 \pm 9.6 \%$ vs. $89.2 \pm 5.9 \%, \mathrm{p}=0.047$ for 5 -year OS) (Fig. 2C). 
A
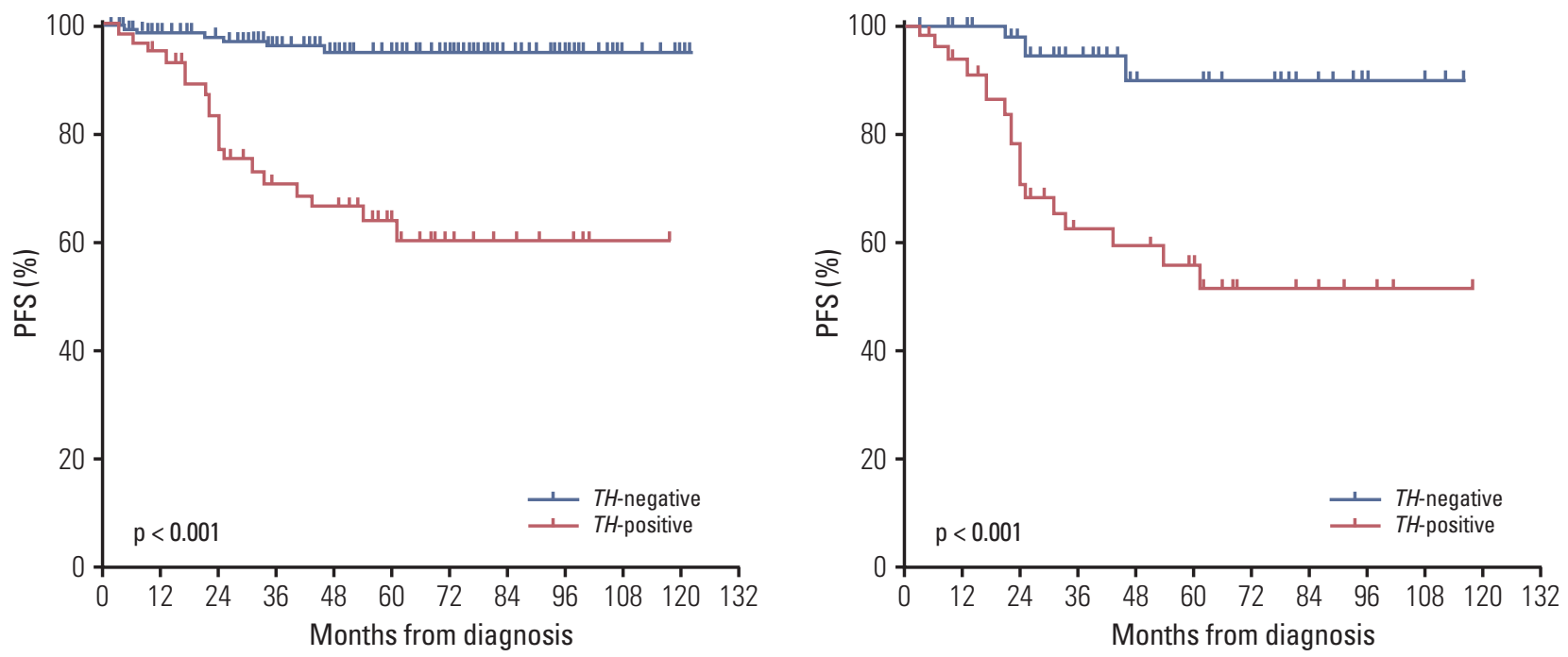

C

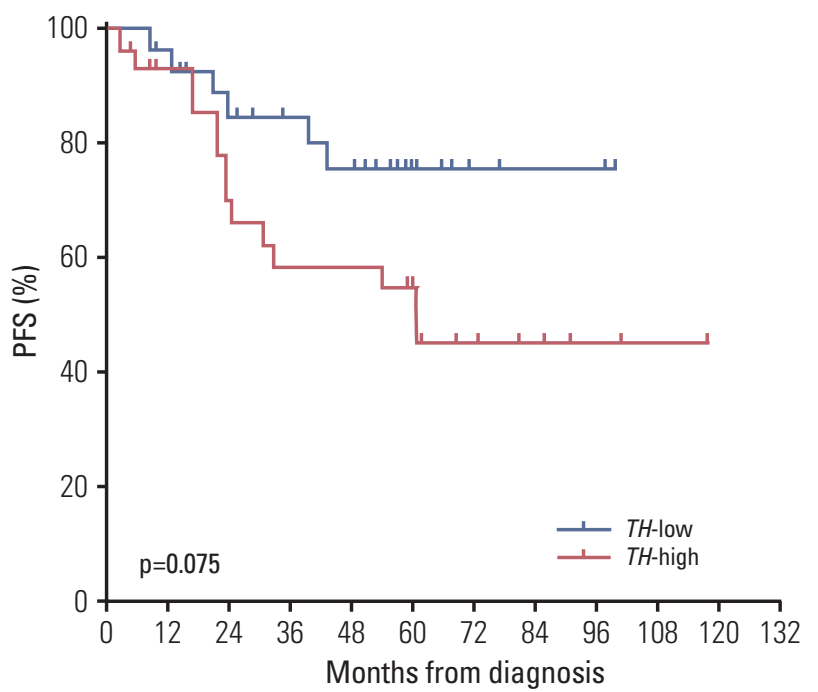

Fig. 2. Survival rates according to tyrosine hydroxylase (TH) expression in peripheral blood at diagnosis. (A) The 5-year progression-free survival (PFS) was lower in TH-positive than in TH-negative patients $(63.8 \pm 6.9 \%$ vs. $94.7 \pm 2.1 \%, \mathrm{p}<0.001)$. (B) In analysis confined to high-risk patients, the probability of 5-year PFS was lower in TH-positive than in TH-negative patients (55.7 $\pm 8.2 \%$ vs. $89.6 \pm 5.8 \%$, $\mathrm{p}=0.001$ ). (C) Among $\mathrm{TH}$-positive patients, a higher expression level of $\mathrm{TH}$ was associated with a worse outcome (above median level vs. below median level: 5 -year PFS, $52.9 \pm 10.0 \%$ vs. $75.7 \pm 8.8 \%$, $\mathrm{p}=0.075$ ).

\section{Discussion}

A number of genetic markers have been investigated for detection of minimal levels of NB cells [13-17]. Viprey et al. [18] reported that the $T H, D C X$, and $P H O X 2 B$ genes are the best candidates for detection of circulating NB cells. Corrias et al. [19], who investigated the advantages of measuring multiple molecular targets over a single molecular target, reported that combinations of multiple targets did not add to the predictive power of $\mathrm{TH}$ analysis alone. Gilbert et al. [20] also reported that $\mathrm{TH}$ might be the one of the most useful molecular targets. In this context, in the current study we measured TH mRNA alone for molecular detection of mini- 
Table 3. Multivariate analysis of factors affecting PFS and OS in all patients

\begin{tabular}{|c|c|c|c|c|c|c|}
\hline \multirow{2}{*}{ Risk factor } & \multicolumn{3}{|c|}{ PFS } & \multicolumn{3}{|c|}{ OS } \\
\hline & HR & $95 \% \mathrm{CI}$ & p-value & HR & $95 \% \mathrm{CI}$ & p-value \\
\hline Age $\geq 12 \mathrm{mo}$ & 0.94 & $0.28-3.18$ & 0.921 & 0.62 & $0.20-1.88$ & 0.395 \\
\hline Stage 4 & 2.51 & $0.70-9.07$ & 0.160 & 4.28 & $1.25-14.63$ & 0.021 \\
\hline Unfavorable pathology & 1.40 & $0.53-3.75$ & 0.499 & 1.32 & $0.47-3.69$ & 0.595 \\
\hline MYCN amplification & 1.12 & $0.44-2.84$ & 0.820 & 2.55 & $1.10-5.92$ & 0.029 \\
\hline PB TH-positive at diagnosis & 6.66 & $2.25-19.72$ & 0.001 & 2.14 & $0.89-5.16$ & 0.089 \\
\hline
\end{tabular}

PFS, progression-free survival; OS, overall survival; $\mathrm{HR}$, hazard ratio; $\mathrm{CI}$, confidence interval; PB, peripheral blood; $\mathrm{TH}$, tyrosine hydroxylase.

Table 4. Multivariate analysis of factors affecting PFS and OS in high-risk patients

\begin{tabular}{|c|c|c|c|c|c|c|}
\hline \multirow{2}{*}{ Risk factor } & \multicolumn{3}{|c|}{ PFS } & \multicolumn{3}{|c|}{ OS } \\
\hline & HR & $95 \% \mathrm{CI}$ & p-value & HR & $95 \% \mathrm{CI}$ & p-value \\
\hline Age $\geq 12 \mathrm{mo}$ & 0.56 & $0.12-2.62$ & 0.458 & 0.27 & $0.07-1.11$ & 0.069 \\
\hline Unfavorable pathology & 1.35 & $0.47-3.89$ & 0.582 & 2.98 & $0.75-11.88$ & 0.122 \\
\hline MYCN amplification & 0.97 & $0.37-2.55$ & 0.949 & 1.84 & $0.75-4.50$ & 0.181 \\
\hline PB TH-positive at diagnosis & 9.02 & $2.06-39.50$ & 0.004 & 3.54 & $1.26-9.93$ & 0.016 \\
\hline
\end{tabular}

PFS, progression-free survival; OS, overall survival; HR, hazard ratio; CI, confidence interval; PB, peripheral blood; TH, tyrosine hydroxylase.

mal disease in all patients who were newly diagnosed with NB.

Positive TH expression in PB at diagnosis was associated with high-risk features and worse outcome. More importantly, positive $\mathrm{TH}$ expression in $\mathrm{PB}$ at diagnosis was an independent poor prognostic factor for PFS. The results were similar when the analysis was confined to high-risk patients. Current staging systems use conventional diagnostic modalities such as CT, MRI, BM biopsy, and various radioisotope scans. Patients are stratified into risk groups based on these staging systems and patients within each risk group are treated uniformly. However, our study showed that outcomes within the high-risk group differ according to $\mathrm{TH}$ expression in PB at diagnosis. Previous studies also reported that positive $\mathrm{TH}$ expression was a poor prognostic indicator in metastatic NB $[13,21,22]$. These findings suggest that $T H$ expression at diagnosis might be a significant factor in future methods of risk stratification for NB. Some studies examined the clinical implication of positive $\mathrm{TH}$ expression in non-metastatic NB $[19,23]$. Yanez et al. [23] reported an association of positive $\mathrm{TH}$ expression in PB at diagnosis with a higher probability of relapse in patients with non-metastatic NB. These findings suggest that some patients with localized tumors (by conventional diagnostic modalities) might have disseminated micrometastatic disease and therefore might benefit from upstaging and more aggressive treatment [24]. However, in the current study, because only one of 10 $\mathrm{TH}$-positive patients with localized tumor experienced relapse, the significance of $\mathrm{TH}$ expression in patients with localized tumors was unclear. Further studies including more patients are needed to evaluate the prognostic importance of $\mathrm{TH}$ expression in the PB of patients with localized tumors.

Among TH-positive patients, higher TH expression was associated with advanced stage and high-risk tumor, but not with older age or MYCN amplification, and a higher $\mathrm{TH}$ expression level at diagnosis was associated with a worse outcome. Yanez et al. [25] reported that a high level of $\mathrm{TH}$ mRNA in PB was a significant independent predictor of event-free survival and OS when detected at diagnosis, postinduction therapy, and at the end of treatment. They proposed inclusion of TH mRNA monitoring throughout the disease course by RT-qPCR as a standard method of disease evaluation that would be helpful in predicting differences in outcome and identify children for whom current treatment is failing or insufficient [25]. The European HR-NBL1/ SIOPEN study defined patients with very high $\mathrm{TH}$ expression as ultrahigh-risk. These ultrahigh-risk patients showed very poor outcome among the group of high-risk NB patients (PFS, 0\%), most of whom underwent single HDCT / auto-SCT 
following short induction treatment. The authors suggested that patients with very high $\mathrm{TH}$ expression are candidates for alternative treatment strategies [22]. In the current study, the prognosis of patients with high $\mathrm{TH}$ expression was also poorer than for those with low TH expression, but was not dismal. The relatively better outcome in our patients with high $\mathrm{TH}$ expression compared to those in the European HR-NBL1/SIOPEN study might be attributable to the longer induction treatment and more intensive consolidation treatment using tandem HDCT/auto-SCT.

\section{Conclusion}

In conclusion, positive $\mathrm{TH}$ expression in $\mathrm{PB}$ at diagnosis of neuroblastoma is associated with high-risk features and is an independent prognostic factor for poor PFS. Results of the current study suggest that treatment intensity should be tailored according to $\mathrm{TH}$ expression in $\mathrm{PB}$ at diagnosis.

\section{Conflicts of Interest}

Conflict of interest relevant to this article was not reported.

\section{Acknowledgments}

This study was supported by a grant from the Korean Health Technology R\&D Project, Ministry of Health \& Welfare, Republic of Korea (No. HI13C1521).

\section{References}

1. Shimada H, Ambros IM, Dehner LP, Hata J, Joshi VV, Roald B. Terminology and morphologic criteria of neuroblastic tumors: recommendations by the International Neuroblastoma Pathology Committee. Cancer. 1999;86:349-63.

2. Brossard J, Bernstein ML, Lemieux B. Neuroblastoma: an enigmatic disease. Br Med Bull. 1996;52:787-801.

3. Fukuda M, Miyajima Y, Miyashita Y, Horibe K. Disease outcome may be predicted by molecular detection of minimal residual disease in bone marrow in advanced neuroblastoma: a pilot study. J Pediatr Hematol Oncol. 2001;23:10-3.

4. Grima B, Lamouroux A, Boni C, Julien JF, Javoy-Agid F, Mallet J. A single human gene encoding multiple tyrosine hydroxylases with different predicted functional characteristics. Nature. 1987;326:707-11.

5. Naito H, Kuzumaki N, Uchino J, Kobayashi R, Shikano T, Ishikawa $\mathrm{Y}$, et al. Detection of tyrosine hydroxylase mRNA and minimal neuroblastoma cells by the reverse transcriptionpolymerase chain reaction. Eur J Cancer. 1991;27:762-5.

6. Miyajima Y, Kato K, Numata S, Kudo K, Horibe K. Detection of neuroblastoma cells in bone marrow and peripheral blood at diagnosis by the reverse transcriptase-polymerase chain reaction for tyrosine hydroxylase mRNA. Cancer. 1995;75: 2757-61.

7. Kuroda T, Saeki M, Nakano M, Mizutani S. Clinical application of minimal residual neuroblastoma cell detection by reverse transcriptase-polymerase chain reaction. J Pediatr Surg. 1997;32:69-72.

8. Burchill SA, Bradbury FM, Selby P, Lewis IJ. Early clinical evaluation of neuroblastoma cell detection by reverse transcriptase-polymerase chain reaction (RT-PCR) for tyrosine hydroxylase mRNA. Eur J Cancer. 1995;31A:553-6.

9. Lee ST, Ki CS, Sung KW, Kim HJ, Kim JW, Kim SH, et al. Molecular detection of tyrosine hydroxylase in the peripheral blood of patients with neuroblastoma: useful at diagnosis but not predictive of subsequent relapse during off-therapy follow-up. Pediatr Hematol Oncol. 2011;28:16-23.

10. Brodeur GM, Pritchard J, Berthold F, Carlsen NL, Castel V, Castelberry RP, et al. Revisions of the international criteria for neuroblastoma diagnosis, staging, and response to treatment. J Clin Oncol. 1993;11:1466-77.

11. Peuchmaur M, d'Amore ES, Joshi VV, Hata J, Roald B, Dehner LP, et al. Revision of the International Neuroblastoma Pathology Classification: confirmation of favorable and unfavorable prognostic subsets in ganglioneuroblastoma, nodular. Cancer. 2003;98:2274-81.

12. Sung KW, Lee SH, Yoo KH, Jung HL, Cho EJ, Koo HH, et al. Tandem high-dose chemotherapy and autologous stem cell rescue in patients over 1 year of age with stage 4 neuroblastoma. Bone Marrow Transplant. 2007;40:37-45.

13. Burchill SA, Lewis IJ, Abrams KR, Riley R, Imeson J, Pearson $\mathrm{AD}$, et al. Circulating neuroblastoma cells detected by reverse transcriptase polymerase chain reaction for tyrosine hydroxylase mRNA are an independent poor prognostic indicator in stage 4 neuroblastoma in children over 1 year. J Clin Oncol. 2001;19:1795-801.

14. Oltra S, Martinez F, Orellana C, Grau E, Fernandez JM, Canete A, et al. The doublecortin gene, a new molecular marker to detect minimal residual disease in neuroblastoma. Diagn $\mathrm{Mol}$ Pathol. 2005;14:53-7.

15. Stutterheim J, Gerritsen A, Zappeij-Kannegieter L, Kleijn I, 
Dee R, Hooft L, et al. PHOX2B is a novel and specific marker for minimal residual disease testing in neuroblastoma. J Clin Oncol. 2008;26:5443-9.

16. Bozzi F, Luksch R, Collini P, Gambirasio F, Barzano E, Polastri $\mathrm{D}$, et al. Molecular detection of dopamine decarboxylase expression by means of reverse transcriptase and polymerase chain reaction in bone marrow and peripheral blood: utility as a tumor marker for neuroblastoma. Diagn Mol Pathol. 2004;13:135-43.

17. Cheung IY, Vickers A, Cheung NK. Sialyltransferase STX (ST8SiaII): a novel molecular marker of metastatic neuroblastoma. Int J Cancer. 2006;119:152-6.

18. Viprey VF, Lastowska MA, Corrias MV, Swerts K, Jackson MS, Burchill SA. Minimal disease monitoring by QRT-PCR: guidelines for identification and systematic validation of molecular markers prior to evaluation in prospective clinical trials. J Pathol. 2008;216:245-52.

19. Corrias MV, Haupt R, Carlini B, Cappelli E, Giardino S, Tripodi G, et al. Multiple target molecular monitoring of bone marrow and peripheral blood samples from patients with localized neuroblastoma and healthy donors. Pediatr Blood Cancer. 2012;58:43-9.

20. Gilbert J, Norris MD, Marshall GM, Haber M. Low specificity of PGP9.5 expression for detection of micrometastatic neuroblastoma. Br J Cancer. 1997;75:1779-81.

21. Trager C, Vernby A, Kullman A, Ora I, Kogner P, Kagedal B. mRNAs of tyrosine hydroxylase and dopa decarboxylase but not of GD2 synthase are specific for neuroblastoma minimal disease and predicts outcome for children with high-risk disease when measured at diagnosis. Int J Cancer. 2008;123: 2849-55.

22. Viprey VF, Gregory WM, Corrias MV, Tchirkov A, Swerts K, Vicha A, et al. Neuroblastoma mRNAs predict outcome in children with stage 4 neuroblastoma: a European HR-NBL1/ SIOPEN study. J Clin Oncol. 2014;32:1074-83.

23. Yanez Y, Grau E, Oltra S, Canete A, Martinez F, Orellana C, et al. Minimal disease detection in peripheral blood and bone marrow from patients with non-metastatic neuroblastoma. J Cancer Res Clin Oncol. 2011;137:1263-72.

24. Burchill SA. Micrometastases in neuroblastoma: are they clinically important? J Clin Pathol. 2004;57:14-20.

25. Yanez Y, Hervas D, Grau E, Oltra S, Perez G, Palanca S, et al. TH and DCX mRNAs in peripheral blood and bone marrow predict outcome in metastatic neuroblastoma patients. J Cancer Res Clin Oncol. 2016;142:573-80. 